\title{
Determinants of pharmaceutical expenditures of urban households: A time series study in Kermanshah province (Iran)
}

Behzad Karami Matin ${ }^{1}$, Saeed Reza Azami², Saeid Mahmoudi ${ }^{3}$, Satar Rezaei ${ }^{4}$, Faramarz Shaahmadi ${ }^{5}$, Ali Kazemi Karyani $^{4}$

${ }^{1}$ Ph.D. of Health Services Management, Associate Professor, Research Center for Environmental Determinants of Health, Kermanshah University of Medical Sciences, Kermanshah, Iran

${ }^{2}$ Ph.D. Student of Health Services Management, Vice Chancellor of Management and Resource Development, Student Welfare Found, Ministry of Health, Tehran, Iran

${ }^{3}$ Ph.D. Student of Health Services Management, Department of Health Management and Economics, School of Public Health, Tehran University of Medical Sciences, Tehran, Iran

${ }^{4}$ Ph.D. Student of Health Economics, Research Center for Environmental Determinants of Health, Kermanshah University of Medical Sciences, Kermanshah, Iran

${ }^{5}$ Ph.D. Student of Health Education and Promotion, Savojbolagh Health Center, Alborz University of Medical Sciences, Karaj, Iran

\section{Type of article: Original}

\begin{abstract}
Introduction: In recent decades, the development of medical and pharmaceutical science has led to a heavy financial burden on the government, insurance companies, and the general population. Due to the increasing the cost of pharmaceutical products in the Kermanshah Province, policy makers have tried to identify the factors that resulted in the increases. The aim of this study was to determine the main factors that affect the expenditures for pharmaceutical products by urban households in Kermanshah Province, Iran.

Methods: This analytical-descriptive study was conducted using time series method. The study population was urban households of Kermanshah Province from 1991 to 2013. The explanatory variables of the log-log model were drug price index (LnDPI), the average income of urban households (LnINC), the number of physicians per 1,000 people (LnPH), and the number of hospital beds per 1,000 people (LnBE). The required data were acquired from the Statistical Center of the Ministry of Health and Medical Education. The unit root was evaluated by the Dickey-Fuller test. Stata v.11 software was used for the statistical analysis.

Results: Coefficients of LnDPI and LnPH were 0.97 and 0.77 , respectively, and they were statistically significant $(p<0.05)$. Also, the coefficients of D. LnINC (first difference of LnINC) and LnBE were 0.34 and 1.8, respectively, and both of them were statistically insignificant ( $p>0.05)$.

Conclusion: The results showed that drugs are non-elastic and essential for households. It should be noted that the health policy makers in Iran should conduct appropriate planning to ensure both the physical and financial accessibility to drugs by urban households. The development of basic and supplementary health insurance coverage, especially for poor populations and urban areas where there are patients with chronic diseases, can be a suitable solution to reduce barriers to acquiring the required drugs.

Keywords: pharmaceutical expenditures, price elasticity, income elasticity, urban households, Kermanshah Province
\end{abstract}

\section{Introduction}

In recent decades, the development of medical and pharmaceutical science has facilitated the treatment of patients by producing new drugs (1). These new drugs have led to an increase in the direct costs of treatment, which has

\section{Corresponding author:}

Ali Kazemi Karyani, Research Center for Environmental Determinants of Health, Kermanshah University of Medical Sciences, Kermanshah, Iran. Tel: +98.9183558225, Email: alikazemi2000@yahoo.com

Received: July 07, 2015, Accepted: August 15, 2015, Published: November 2015

iThenticate screening: August 01, 2015, English editing: August 26, 2015, Quality control: November 08, 2015

(C) 2015 The Authors. This is an open access article under the terms of the Creative Commons Attribution-NonCommercialNoDerivs License, which permits use and distribution in any medium, provided the original work is properly cited, the use is non-commercial and no modifications or adaptations are made. 
imposed a heavy financial burden on the government, insurance companies, and the general population $(2,3)$. According to statistics provided by the World Health Organization (WHO), Iran is among the top 20 countries in the world with respect to the consumption of drugs (4). Per capita pharmaceutical expenditures in Iran make up 19.5\% of total healthcare expenditures (5). In Iran, the total cost of the medicines consumed in 1998 was more than 750 million USD, and, by 2012, it has almost tripled, reaching about 2.2 billion USD (6). Pharmaceutical expenditures and the costs associated with drug consumption are about $30 \%$ of the total expenditures for healthcare, and it is nearly $50 \%$ of outpatient care expenditures in many developing countries (4). However, in most member countries of the Organization for Economic Co-operation and Development (OECD), the share of drug costs is less than 10\%. The statistics also show that the share of expenditures for outpatient care (as opposed to hospital care) is $60 \%$ in Iran, while it is $30 \%$ in developed countries. The statistics show that, despite the growth and expansion of the production and sales of pharmaceutical products in Iran, people in Iran must pay about $65 \%$ of the total cost of the drugs they must have (4). These high out-of-pocket costs for drugs in the healthcare system are indicative of the importance of drugs in the country's healthcare policy $(7,8)$. In order to have a proper pharmaceutical policy and timely reforms, accurate information must be available concerning the demand for drugs and the factors that affect this demand $(9,10)$. Determination of the factors that affect the use of healthcare services is one of the aims of demand analysis in the health sector (11). Some studies have estimated the demand for drugs by urban and rural households in Iran, e.g., Emamgholipour et al. (12), Ravangard et al. (13), Rahbar et al. (14), and Ebadi Fardazar et al. (15). They studied the factors that affect the demand for drugs, including household income, drug prices, and other factors. The factors that affect drug demand vary at different times and places. Having appropriate information about the factors that affect the demand for drugs at the local level is very important for making effective policies in this field, and, in fact, it is required for the development and implementation of proper policies and programs to manage expenditures for drugs (16-18). In this study, the demand for drugs was estimated using data for Kermanshah Province acquired from the Statistical Center of the Ministry of Health and Medical Education of Iran and the time series method for the period of 1991 to 2013. This study can supply appropriate information about the factors that affect the demand for drugs in Kermanshah Province. In this study, we developed answers for the following research questions:

1) What is the price elasticity of drug demand?

2) What is the income elasticity of drug costs?

3) What effect does the number of physicians per capita have on pharmaceutical expenditures?

4) What effect does the number of hospital beds per capita have on pharmaceutical expenditures?

\section{Material and methods}

This analytical-descriptive study was conducted using the time series method. Earlier studies conducted in this field were investigated, and the variables were identified to determine the equation of drug demand for households in Kermanshah $(12-15,19)$. The explanatory variables of the model were drug price index, the average income of urban households, the number of physicians per 1,000 people, and the number of hospital beds per 1,000 people. The required data were collected from the Statistical Center of the Ministry of Health and Medical Education of Iran. The overall model was as follows: PHE $=\mathrm{f}(\mathrm{DPI}, \mathrm{HI}, \mathrm{PH}, \mathrm{BE})$, where PHE is average pharmaceutical expenditures in urban households, DPI is the drug price index, INC is the average income in urban households, PH is the number of physicians per 1000 people, and BE is the number of hospital beds per 1000 people. This can be converted to the Cobb Douglas equation, i.e., PHE $=\beta 1$ DPI $\beta 2 \mathrm{t} \times \mathrm{INC} \beta 3 \mathrm{t} \times \mathrm{PH} \beta 4 \mathrm{t} \times \mathrm{BE} \beta 5 \mathrm{t}$. This equation can be rewritten as shown below by taking the log of the latter equation. The advantage of the revised form of the equation is that the model becomes linear and multi-collinearity between the variables is reduced. Also, the coefficients of each variable can be interpreted by the elasticity of pharmaceutical expenditures related to that variable. Thus, the equation becomes $\operatorname{LnPHE}=\beta 1+\beta 2 \operatorname{lnDPIt}+\beta 3 \ln I N C t+\beta 4 \ln P H t+\beta 5 \ln B E t+\varepsilon$. The coefficient of the dependent variable is the elasticity of the dependent variable on the log-log models. Here, the variable of pharmaceutical expenditures (PHE) can be calculated by the price per drug multiplied by the amount of drugs $\left(\mathrm{P}^{*} \mathrm{Q}\right)$. $\beta 2$ is the price elasticity of pharmaceutical expenditures, and therefore $1-\beta 2$ is the price elasticity of demand. Similarly, $\beta 3$ is the income elasticity of pharmaceutical expenditures, $\beta 4$ is the elasticity of pharmaceutical expenditures to the number of physicians per capita, and $\beta 5$ is pharmaceutical expenditures to the number of beds per capita. To analyze the final equation, first an ordinary least squares (OLS) estimator was used to evaluate the equation. Then, the existence of multi-collinearity between the variables was investigated by using the variance inflation factor (VIF) test for the variables. The first-order difference of income logarithm was used in the equation instead of the income logarithm to eliminate multi-collinearity. The unit root was evaluated by the Dickey-Fuller test. Zero hypothesis implies the existence of a unit root (the nonstationary of variable) (20). The Breusch-Pagan test was used to examine 
heteroskedasticity. Also, the Ramsey RESET test for omitted variables in the model and the Breusch-Godfrey LM test for autocorrelation were conducted (20). The data were analyzed using Stata v.11 software.

\section{Results}

The results of the Dickey-Fuller test for variables in the model, which considers the stationary of variables, are shown in Table 1. The test statistics for lnPHE and lnDPI were -2.68 and -3.59 , respectively. The Dickey-Fuller statistic for the variable of lnINC was -2.05 . Therefore, this variable wasn't stationary. The test statistics for LnPH and LnBE were -8.14 and -3.23 , respectively, and they were stationary. Table 2 presents the results of the VIF test for the variables. The results in the table show that there is multi-collinearity between the variables of the model and that it is primarily due to the LnINC variable. The first-order difference of income was used to solve this problem, thereby eliminating the multi-collinearity between the variables (mean VIF $=7.72$ ). Furthermore, the statistic of the Dickey-Fuller test was equal to -4.77 for the D. LnINC variable, so the problems of a non-stationary primary variable and multi-collinearity between the variables in the model have been solved by substituting the D. LnINC variable for the LnINC variable. The results of the Breusch-Pagan test showed that the variance of the residuals from the regression model were dependent on the values of the independent variables and that there was no heteroskedasticity in the model (Chi-squared $=0.39, \mathrm{p}=0.5318$ ). The Ramsey RESET test showed that our model omitted no variables. Also Breusch-Godfrey LM indicated that there was no serial correlation in the model (Chisquared $=4, p=0.527$ ). Table 3 shows the results of estimation provided by the regression model. According to this table, the coefficient of lnDPI was 0.97 and it was significant at the level of 0.01 . The coefficient of D. LnINC was 0.34, and it was statistically insignificant. The coefficient of the LnPH coefficient was 0.77, and it was significant at the level of 0.05 . The coefficient of LnBE was 1.8, and it was statistically insignificant. Therefore, the price elasticity of pharmaceutical expenditures and the price elasticity of demand were 0.97 and 0.03 , respectively. This means that by changing the price of drug by $1 \%$, drug expenditures and pharmaceutical demand change 0.97 and 0.03, respectively. Adjusted R-squared, or the goodness of fit, for final model was 0.99, and F-statistics of the model was equal to 726.59 , and it was statistically significant $(\mathrm{p}<0.000)$.

Table 1. Results of the Dickey-Fuller test for the variables

\begin{tabular}{|l|l|l|l|l|}
\hline \multirow{2}{*}{ Variables } & Test statistics & \multicolumn{3}{|l|}{ Interpolate Dickey-Fuller } \\
\cline { 3 - 5 } & & $1 \%$ critical value & $5 \%$ critical value & $10 \%$ critical value \\
\hline LnPHE & -2.68 & -3.75 & -3.00 & -2.63 \\
\hline LnDPI & -3.59 & -3.75 & -3.00 & -2.63 \\
\hline LnINC & -2.05 & -3.75 & -3.00 & -2.63 \\
\hline LnPH & -8.14 & -3.75 & -3.00 & -2.63 \\
\hline LnBE & -3.23 & -3.75 & -3.00 & -2.63 \\
\hline
\end{tabular}

Table 2. Results of VIF test for multi-collinearity

\begin{tabular}{|l|l|l|l|l|l|}
\hline Variables & VIF & 1/VIF & Variables & VIF & $1 /$ IF \\
\hline LnDPI & 43.44 & 0.023 & LnDPI & 14.00 & 0.071 \\
\hline LnHI & 43.96 & 0.022 & D. LnHI & 14.21 & 0.70 \\
\hline LnPH & 4.42 & 0.226 & LnPH & 1.34 & 0.743 \\
\hline LnBE & 1.66 & 0.22 & LnBE & 1.34 & 0.745 \\
\hline Mean VIF & 23.37 & Mean VIF & 7.72 \\
\hline
\end{tabular}

Table 3. Results of estimation by the regression model

\begin{tabular}{|l|l|l|l|l|}
\hline Variables & Coefficients & Std. Err. ${ }^{*}$ & $\mathrm{t}$ & p-value \\
\hline LnDPI** & 0.97 & 0.082 & 11.89 & 0 \\
\hline D. LnINC & 0.34 & 0.307 & 1.14 & 0.274 \\
\hline LnPH*** & 0.77 & 0.313 & 2.48 & 0.026 \\
\hline LnBE & 1.8 & 1.41 & 1.32 & 0.207 \\
\hline constant & 2.63 & 0.337 & 7.83 & 0 \\
\hline Adjusted R-squared & 0.99 & \multicolumn{4}{|l|}{} \\
\hline
\end{tabular}

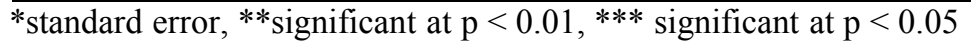




\section{Discussion}

The results of this study showed that the price elasticity of pharmaceutical expenditures was 0.97 for the urban households of Kermanshah Province. So, with a $1 \%$ increase in the price of a drugs pharmaceutical expenditures will increase by $0.97 \%$. The results also showed that demand for pharmaceutical products was non-elastic, and they are considered to be essential items by urban households. The study by Emamqolipour Sefiddashti et al. showed that the price elasticity of drug expenditures were 0.08 and 0.63 for urban and rural households, respectively (12). Ravangard's study, which was conducted by using time series, showed that the price elasticity of pharmaceutical expenditures was less than one (13). There also other studies that have shown drugs to be necessary commodities for households in Iran, e.g., Nouri Motlagh et al. (19), EbadifardAzar et al. (15), and Rahbar et al. (14). One study showed that drugs were non-elastic to the elderly and rich Australians (21). A study conducted by Shea et al. examined the effect of insurance coverage on the use of prescription drugs by Medicare beneficiaries, and it showed that the price elasticity of prescription drugs was -0.54 (23). In general, it can be said that drugs are non-elastic as are most goods and services in healthcare, so the demand for pharmaceutical products cannot be reduced by increasing their cost. Thus, policies intended to control pharmaceutical expenditures by increasing the prices of drugs have little impact, and it is possible that they increase out-of-pocket payments, especially in households without adequate insurance coverage. One of the topics that should be considered in demand for goods and healthcare services is the agency's issue. This means that most of users of these services don't have enough knowledge and information to decide on the purchase of these goods and services. Therefore, they concede their decision to physicians and health professionals. So, one of the most important supply-side controlling policies is to monitor the behavior of health providers and control the demand induced by the health sector. The pharmaceutical expenditures of households can be controlled largely by replacing expensive drugs with less-expensive drugs that provide the same benefit (e.g., generic drugs), encouraging physicians to prescribe these drugs, and strategic purchasing by drug providers. Various policies, including educating people in the community, can be used to control the demand side $(13,24-26)$. Household income is another factor that affects expenditures for pharmaceutical products.

According to our findings, expenditures for these products increase as the household's income increases. Emamgholipour et al. showed that the income elasticity of pharmaceutical expenditures for urban and rural households in Iran were 0.35 and 0.95 , respectively (12). Also, Ravangard et al. determined this number to be 0.73 by using the budget-household data with the time series method (13). Ebadifard Azar et al. found that the income elasticities of pharmaceutical expenditures for urban and rural households were $0.42 \%$ and $0.59 \%$, respectively (15). Jahangiri's study also showed that the income elasticity of pharmaceutical demand was less than one (1). So, it can be said that drugs are essential for households, and the demand for pharmaceutical products is expected to increase as the household income increases. Our findings showed that the number of physicians per 1,000 people had a significant influence on increasing pharmaceutical expenditures. Increasing the number of physicians in the community leads to improved accessibility to healthcare. Physicians usually prescribe drugs when they see patients, so prescription drugs, and thus pharmaceutical expenditures, will increase as the number of physicians and medical visitations increase. Most pharmaceutical expenditures were for prescription drugs. Therefore, pharmaceutical expenditures can be reduced significantly by training physicians and changing their behaviors concerning prescriptions through various strategies, such as retraining courses, introducing cost-effective drugs, and encouraging them to prescribe generic drugs (27).

One of our findings was that the number of hospital beds had no significant influence on increasing pharmaceutical expenditures. The number of hospital beds elasticity of pharmaceutical expenditures was 1.8 , meaning that a $1 \%$ increase in number of hospital beds per 1000 people, average pharmaceutical expenditures of urban households will increased by $1.8 \%$. Drugs are one of the most important medical supplies in the hospital, so the use of drugs increases when the number of hospital beds and admissions increase. There also can be several ways to control pharmaceutical expenditures, such as monitoring the necessity of hospitalization, controlling hospital prescription drugs, and promoting the use of generic drugs and other cost-effective drugs in hospitals. Other factors that can have a significant impact on controlling pharmaceutical expenditures are improving the referral system, control and modification of prescription behavior, investment in the production of cost-effective drugs, limiting imports of unnecessary drugs, and educating the public. Due to the lack of access to some data in this study, it was impossible to investigate some of the important variables in the model, such as the type and amount of coverage of basic health insurance, supplemental insurance, separation of the demand for inpatient and outpatient treatment, the number of medical visits, and the demand for specific types of pharmaceutical products. So, it is recommended that the impact of other variables on the pharmaceutical demand be considered in future studies. 


\section{Conclusions}

The findings of this study showed that the price elasticity of drugs was close to zero and income elasticity of drugs was less than one for households in Kermanshah Province. Therefore, drugs are non-elastic and essential for urban households. Pharmaceutical expenditures of households also are increased by increasing the numbers of physicians and hospital beds per capita. It should be noted that the health policy makers should plan appropriately to ensure the physical and financial accessibility to drugs by the households of Kermanshah Province. The development of basic and supplementary health insurance coverage, especially for poor populations, rural areas, and patients with chronic diseases, can be a suitable solution to enhance their accessing the drugs they need. Therefore, the development and implementation of appropriate monitoring policies should be considered to prevent the loss of healthcare resources and reduce pharmaceutical expenditures for households. There are several strategies that can be used to control pharmaceutical expenditures, such as correcting and controlling the behaviors of physicians with respect to writing prescriptions, reducing the induced demand, retraining physicians and medical staff, monitoring pharmacies to stop selling non-prescription drugs, replacing generic drugs with brand drugs, limiting the import of non-essential drugs, investment in the production of cost-effective drugs in the country.

\section{Acknowledgments:}

This article is the result of a research project number 93339 approved in 2014 by the Deputy of Kermanshah University of Medical Sciences, who also funded this research. The authors appreciate the support provided by the Deputy of Research and the assistance of the University staff and others who provided input and helped us in conducting this research.

\section{Conflict of Interest:}

There is no conflict of interest to be declared.

\section{Authors' contributions:}

All authors contributed to this project and article equally. All authors read and approved the final manuscript.

\section{References}

1) Jahangiri G. Estimating the demand for drugs in the Iranian economy (MSc thesis). Tehran University; 1996 (Persian).

2) Ghanati E, Hadiyan M , Daghighi AR. Economic expenditures of multiple sclerosis medications and feasibility of providing health insurance policies for medications. Journal of Health Administration. 2011; 14(45): 37-54. Available from: http://jha.iums.ac.ir/browse.php?mag id=45\&slc lang=en\&sid=1.

3) Javidannezhad S. Drug information. Printing and Publication Institute of Tehran University, 1 st ed, 1991. (Persian)

4) Amani F, Shaker A. Patterns of drug use among urban households in Ardabil. Payavard Salamat, ISSN: 2008-2665. 2011; 5(5): 33-41 .Available from: http://payavard.tums.ac.ir/search.php?slc_lang=en\&sid=1.

5) Baldini CG, Culley EJ. Estimated cost savings associated with the transfer of office-administered specialty pharmaceuticals to a specialty pharmacy provider in a Medical Injectable Drug program. J Manag Care Pharm. 2010; 17(1): 51-9, PMID: 21204590.

6) Kebriaeezadeh A, Koopaei NN, Abdollahiasl A, Nikfar S, Mohamadi N. Trend analysis of the pharmaceutical market in Iran; 1997-2010; policy implications for developing countries. Daru J Pharm Sci. 2013; 21: 52. doi: 10.1186/2008-2231-21-52, PMID: 23805853, PMCID: PMC3718624.

7) Golestani M, Rasekh H, Imani A. The relationship between pharmaceutical expenditures, health care expenditures and gross domestic product in Iran: 1999-2008. Pharmaceutical Sciences. 2012; 18(1): 9-17.

8) Islamic Parliament Research Center of Iran, The study of the pharmaceutical industry after the Islamic Revolution of Iran. 2006. Available from: http://rc.majlis.ir/fa/report/show/733366.

9) Homaie Rad E, Vahedi S, Teimourizad A, Esmaeilzadeh F, Hadian M, Torabi Pour A. Comparison of the effects of public and private health expenditures on the health status: a panel data analysis in eastern mediterranean countries. Int J Health Policy Manag. 2014; 1(2): 163-7. doi: 10.15171/ijhpm.2013.29, PMID: 24596857, PMCID: PMC3937925.

10) Baily MN. Research and development costs and returns: the US pharmaceutical industry. J Polit Econ. 1972; 80: 70-85. Available from: http://www.jstor.org/stable/1830132?seq=1\#page_scan_tab_contents. doi: $/ 10.1086 / 259862$ 
11) Blazer DG, Wu L-T. The epidemiology of at-risk and binge drinking among middle-aged and elderly community adults: National Survey on Drug Use and Health. Am J Psychiatry.2009; 166 (10): 1162-9. doi: 10.1176/appi.ajp.2009.09010016, PMID: 19687131.

12) Emamgholipour Sefiddashti S, Rashidian A, Nakhaee M. Estimation of Medication Demand Function in Iranian Households using Panel Data, 2004-2011. Hakim Research Journal. 2014; 17(3): 235-41. Available from: http://www.hakim.hbi.ir/browse.php?a_id=1369\&sid=1\&slc_lang=en

13) Ravangard R, Jafari A, Motlagh SN. Drug demand function for Iranian urban households based on households' budget. Health Scope. 2014; 3(3): 18494.

14) Rahbar A, Barouni M, Bahrami M, Saber Mahani A. Estimation of Drug Demand Function in Iranian Urban Population through Household Budget, 1990-2011. Toloo-e-behdasht. 2013; 12(3):44-58. Available from: http://tbj.ssu.ac.ir/browse.php?a_code $=\mathrm{A}-10-422-1 \&$ slc_lang $=$ en \&sid=1\&sw=Health.

15) EbadifardAzar F, Rezapoor A, Rahbar A, Hosseini Shokouh SM. Estimation of the Function of Medicine Demand in Islamic Republic of Iran. J Mil Med. 2013; 15(2): 163-8.

16) Samadi A, Homaie Rad E. Determinants of Healthcare Expenditure in Economic Cooperation Organization (ECO) Countries: Evidence from Panel Cointegration Tests. Int J Health Policy Manag. 2014; 1(1): 63-8. doi: 10.15171/ijhpm.2013.10, PMID: 24596838, PMCID: PMC3937933.

17) Abolhalaj M, Bastani P, Ramezanian M, Tamizkar N. Production and consumption financial Process of drugs in Iranian healthcare market. Develop Countr Stud. 2013; 3(1): 187-91. Available from: http://www.iiste.org/Journals/index.php/DCS/article/view/3898.

18) Radyowijati A, Haak H. Improving antibiotic use in low-income countries: an overview of evidence on determinants. SOC SCI MED. 2003; 57(4): 733-44. doi: 10.1016/S0277-9536(02)00422-7.

19) Nouraei Motlagh S, Rezapour A, Lotfi F, Safari H, Hadian M. Factors Influencing Pharmaceutical Demand in Iran: Results from a Regression Study. International Journal of Hospital Research. 2014; 3(2): 93-6. Available from: http://ijhr.iums.ac.ir/index.php/index/help/view/editorial/topic/journal/journal/article_6125_1009.html.

20) Verbeek M. A guide to modern econometrics, 4th ed. John Wiley \& Sons 2012. ISBN : 978-1-119-95167-4.

21) Smith DG. The effects of copayments and generic substitution on the use and costs of prescription drugs. Inquiry. 1993: 189-98, PMID: 8314607.

22) Contoyannis P, Hurley J, Grootendorst P, Jeon SH, Tamblyn R. Estimating the price elasticity of expenditure for prescription drugs in the presence of non-linear price schedules: an illustration from Quebec, Canada. Health Econ. 2005; 14(9): 909-23. doi: 10.1002/hec.1041, PMID: 16127675.

23) Shea DG, Terza JV, Stuart BC, Briesacher B. estimating the effects of prescription drug coverage for Medicare beneficiaries. Health Serv Res. 2007; 42(3): 933-49, PMID: 17489897, PMCID: PMC1955253.

24) McPake B, Banda EEN. Contracting out of health Services in developing countries. Health Policy Plan. 1994; 9(1): 25-30. doi: 10.1093/heapol/9.1.25, PMID: 10133098.

25) WHO/DAP. Competitive mechanisms for public drug supply: options, issues, and cautions (working draft). Geneva: World Health Organization; 1997.

26) Folland S, Goodman AC, Stano M. The economics of health and health care, 5th ed. Pearson Prentice Hall New Jersey, 2007. ISBN-0-13-227942-8, PMCID: PMC2375556.

27) Haas JS, Phillips KA, Gerstenberger EP, Seger AC. Potential savings from substituting generic drugs for brand-name drugs: medical expenditure panel survey, 1997-2000. Ann Intern Med. 2005; 142(11): 891-7. doi: 10.7326/0003-4819-142-11-200506070-00006, PMID: 15941695. 